\title{
Mandated CSWB planning in Ontario: A welcome milepost on a continuing journey
}

\author{
Norman E. Taylor*
}

In January of this year, the Canadian province of Ontario enacted into law a mandate for all municipalities to develop and implement collaborative plans for community safety and well-being. The lever for compliance was anchored through a legislative update to the Police Services Act (1990), but the reach of this mandate extends well beyond the police. The requirements are set out to reflect collaborative ideals and to achieve a broad, all-perils-and-all-strengths scope in these plans by establishing base criteria for specific and multi-sector representation on the community advisory committees that will guide them (MCSCS, 2019a, p. 21).

This is no small thing, and it has been many years in the making.

\section{The Early Steps}

The potential to enhance public safety through direct municipal leadership came clearly into focus for Canadian policing about a decade ago, when a Canadian Association of Chiefs of Police (CACP) global studies cohort entitled their summary research report "Police Capacity in Canada: Scarce Resources or Infinite Potential" (ISIS, 2008). Their work showcased examples from Western Europe, where the obligation upon city leaders to engage all relevant service providers in community safety planning was taking root. As that report's title implies, much of the early appeal for Canadian police leaders and governing bodies derived from growing concerns about the economics of policing. But the next year, while examining solutions to youth violence in a wider-ranging global study, it became increasingly evident to another CACP team that collaborative community-led solutions were not just about alleviating strain on front-line police resources. They were also showing significant positive impact on a wide range of health and social outcomes in countries such as Scotland, the United Kingdom, The Netherlands, Colombia, and other South American countries (ISIS, 2009).

At the same time, the early work of the Canadian Municipal Network on Crime Prevention (CMNCP) was maturing into a formidable movement (CMNCP, 2018), with increasing calls for "strong political will" to embrace the concept of a "centre of municipal responsibilities." And, with many factors other than crime as their focus, public health, mental health, addictions, social services, housing, and education sectors were each in their own way seeking more effective and sustainable ways to fulfill their mandates to greater effect, amid a common pressure to hold the line on public service budgets.

There was, as a result, a certain inevitability that each sector would begin to see both the necessity and new potential to engage others in a common cause. In recent years, that common cause has become widely recognized in Canada as community safety and well-being (CSWB) and, in other parts of the world, as the intersection among law enforcement and public health (LEPH) solutions for the benefit of individuals, families, and communities (GLEAPHA, 2017).

\section{The Promise at this Milepost}

Now, as the first of its kind in Canada, the Ontario CSWB planning mandate firmly anchors these collaborations as an essential role of local governments. The protective factors and supportive systems that are designed to keep people healthy are very often the same ones that keep them safe and free from victimization and harm. The compound risk factors that lead some people into lives of addiction and/or homelessness and/ or crime are very often the same risks that lead to poor health, and those that weaken early childhood development and educational attainment. Now, in Ontario at least, every municipal council must find ways to have all of these factors examined through multiple and overlapping lenses and, further, to guide the crafting and mobilization of holistic solutions informed by the evidence to better meet the needs of all its citizens.

For a deeper understanding of the CSWB planning processes being recommended by the province, as well as the tools being provided to communities to fulfill their mandates, interested readers may wish to consult the guidebook recently published by the Ministry of Community Safety and Correctional Services (MCSCS, 2019b).

\section{Some Continuing Challenges Ahead}

While only one province to date has taken this step to mandate local CSWB planning, across Canada almost every province and territory is seeing a growing uptake of similar collaborative models, practices that are also extending into many First Nations communities, urban and reserve (note that

Correspondence to: Norman E. Taylor, Journal of Community Safety and Well Being, Community Safety Knowledge Alliance (CSKA), 111 Research Drive, Suite 105, Saskatoon, SK S7N 3R2.

E-mail: ntaylor@cskacanada.ca. 
under the new Ontario policy, First Nations are encouraged, but not mandated to comply). Several consistent challenges are emerging as this experience grows in Canada and abroad, and the priority attention may soon need to shift beyond the mobilizing phase and turn more intensely into three areas of common concern that will be essential to sustained impact and successful outcomes.

True and Sustained Change in the Collaborative Space Consistent and effective collaboration does not happen automatically, whether mandated or enthusiastically embraced by local champions. It can be hampered by competitive funding frameworks that often lead to boundary management behaviours taking precedence over system alignment. Professionals who are heavily invested in single-sector or bilateral initiatives, and justifiably proud and protective of their demonstrated success, must find reassurance that broader collaborative ventures will not diminish but, rather, will seek to enhance and build on those efforts. In addition, mid-manager accountabilities for programs, budgets, and standard operating procedures often bring the staff members working at the front lines of innovation into friction with the conventional expectations and directions they receive from their organizational leads. It will continue to be imperative that executive system leaders take an eyes wide open posture as they seek to open those boundaries, attend to differences in workplace cultures, and permit and empower true collaboration across sectors. Training and support on the new rules of engagement may become important to the sustained effectiveness and professional satisfaction of all members who are expected to forge new solutions together with their partners.

\section{Access to Data, Multi-sector Analytics, and Cautious Sharing of Information}

No matter how well intentioned, even the most collaborative professionals cannot see in the dark. To bring real meaning and value to these plans, they must be informed by the realities and not merely by popular perceptions of community issues, or by single-silo indicators of need. What has been learned from several years of experience at hub and situation tables, as just one CSWB example, is that risk factors are often cumulative in the lives of those who most need the support of the system, and when these factors are understood in their composite nature, truly effective interventions and lasting care solutions become possible. Similarly, strength building at the individual, family, or neighbourhood level often calls for an accurate understanding of the operating conditions that only cross-sector data analysis can reveal. Collaborative planning and action will require sharing of information at the de-identified level and the consent level and, in acute situations, may require limited sharing at the level of implied consent. Community advisors will want clear and agreed-upon guidelines for their participation, they may need to explore emerging methods for protecting data while learning from it, and at all times, individual and family privacy rights must be carefully balanced with community safety and well-being imperatives.

Adequate investments in essential and equitable services The ultimate challenge to community leaders may be best captured by these troubling questions: What if it actually works? What will we do if we discover that our current investments are misdirected? What if the data reveals not just gaps, but chasms in our available supports to those who need them most? What if we discover that our system is so under-resourced in critical areas of composite need that the conditions on the street that worry us most are beyond our current abilities to respond?

One hopes that in a majority of cities, towns, and regions, many solutions will exist in the form of realignment and service innovation, as is the essential promise of collaborative CSWB plans. But, particularly in rural, remote, and many reserve environments, where essential services and infrastructure may be scarce or difficult to access, such plans may simply reveal what many in those communities already know. A commitment to community CSWB planning must be accompanied by open minds and a readiness to truly address service inequities and deficiencies where they can be addressed. Moreover, mandatory community planning must find its emphasis in the word community, with empowerment to decide and act locally, and with self-determination of community aspirations at its core.

With the Ontario mandate now calling for CSWB plans to be in place and implementation actions to be underway in all municipalities by January 2021, these continuing priority challenges take on a real and urgent nature. They also establish a natural and compelling agenda for researchers and evaluators, whose work continues to be essential to long-term measurable success, knowledge exchange, and continuous improvement supported by objective evidence.

\section{In Closing}

This milepost achievement calls for due credit to the Government of Ontario and, in particular, to the leadership and funding supports provided through MCSCS to many earlyadopter and experimenting communities over the past several years. It also calls for courage on the part of the local planners and implementers who must now implement more formality and structure to augment, and in some cases refocus, their many individual and collaborative efforts and innovative local programs under a somewhat prescribed framework. One hopes that such existing initiatives will be both respected and fully harnessed under this new process.

Finally, while the hard work is just beginning under this bold new public policy, it already carries new hope to those whose daily quality of life too often depends upon a well-integrated system that is genuinely committed to understanding and meeting their true needs for health, safety, and well-being. Here's hoping it proves to be a model of success for other jurisdictions to follow.

\section{CONFLICT OF INTEREST DISCLOSURES}

The author has continuing business interests that include providing advisory services to communities, police services and related human service agencies.

AUTHOR AFFILIATIONS

*Editor-in-Chief, Journal of Community Safety and Well-Being.

\section{REFERENCES}

CMNCP. (2018). CMNCP history. The Canadian Municipal Network on Crime Prevention. Retrieved March 8, 2019, from http://safercities. ca/cmncp-history/ 
GLEAPHA. (2017). The Issues. Global Law Enforcement \& Public Health Association Inc. Retrieved March 8, 2019, from https://gleapha. wildapricot.org/issues

ISIS. (2008). Policing capacity in Canada: Scarce resources or infinite potential? Final report of the Institute for Strategic International Studies. Ottawa: Canadian Association of Chiefs of Police. Retrieved March 8, 2019, from http://cacpglobal.ca/index.php/cohorts/2014-11-07-17-17-19

ISIS. (2009). The Intervention Zone: Youth violence and its extremes - Prevention and enforcement in a new zone of opportunity. Final report of the Institute for Strategic International Studies. Ottawa: Canadian
Association of Chiefs of Police. Retrieved March 8, 2019, from http:// cacpglobal.ca/index.php/cohorts/2014-11-07-17-13-28

MCSCS. (2019a). Community Safety and Well-Being Planning Framework: A Shared Commitment in Ontario. Government of Ontario, p. 21. Retrieved March 8, 2019, from https://www.mcscs.jus.gov.on.ca/ english/Publications/MCSCSSSOPlanningFramework.html

MCSCS. (2019b). Community Safety and Well-Being Planning Framework: A Shared Commitment in Ontario. Government of Ontario. Retrieved March 8, 2019, from https://www.mcscs.jus.gov.on.ca/english/ Publications/MCSCSSSOPlanningFramework.html 